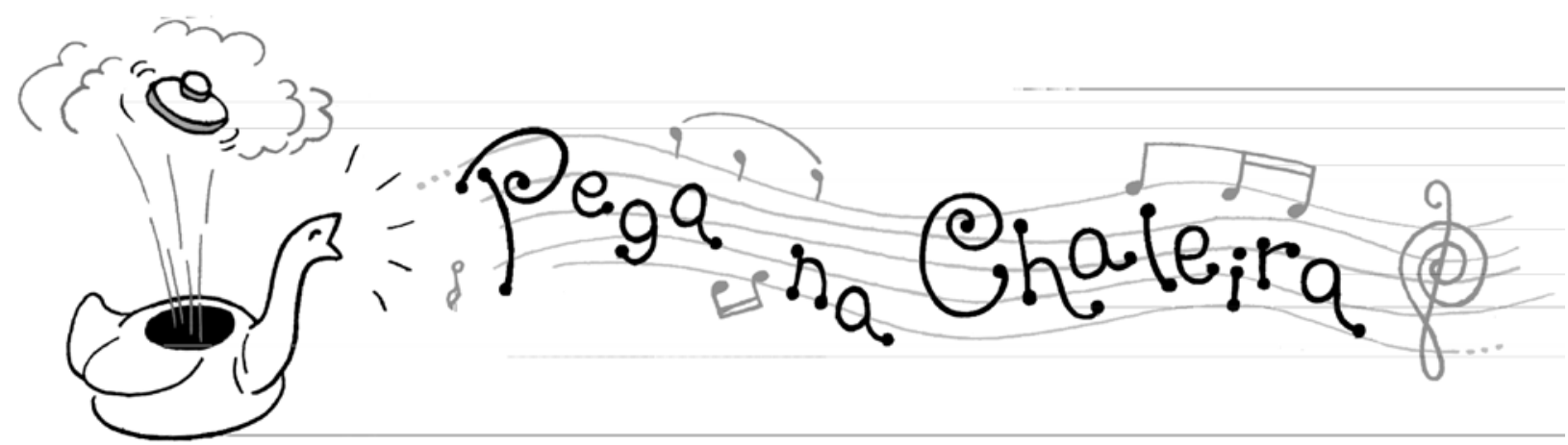

PEGA NA CHALEIRA - RESENHAS

\title{
Leituras sobre música, as palavras e a voz
}

\author{
Maurilio Andrade Rocha (UFMG, Escola de Belas-Artes, Belo Horizonte, MG) \\ mauriliorocha13@gmail.com
}

Resenha do livro CLAYTON, Martin (Ed.). Music, Words and Voice: A Reader. Manchester and New York: Manchester University Press, 2008. 313p. US\$ 26 nos EUA; R\$ 60,63 no Brasil.

Palavras-chave: canto; voz; fala e música; texto e música; etnomusicologia; sociologia da música.

\section{Music, words and voice: a reader}

Review of the book CLAYTON, Martin (Ed.). Music, Words and Voice: A Reader. Manchester and New York: Manchester University Press, 2008. 313p. US\$ 26 nos EUA; R\$ 60,63 no Brasil.

Keywords: singing; voice; speech and music; text and music; ethnomusicology; sociology of music.

A coletânea Music, Words and Voice: A Reader, editada em 2008 por Martin Clayton, foi inicialmente idealizada para servir de fonte bibliográfica para os alunos do seminário Words and Music, oferecido pelo editor na Open University. Assim, o livro reúne trinta e seis textos bastante diversificados, apresentados de forma parcial ou na íntegra e organizados em cinco partes que abordam as relações entre a voz, as palavras e a música dentro de variados gêneros musicais e contextos culturais. 0 volume apresenta diversas transcrições de exemplos musicais, fragmentos de letras de canções, indice remissivo e pode ser adquirido pela internet por cerca de £12.00.
Na primeira parte do livro, denominada de Words and Music, o editor reúne sete trabalhos que discutem as diferenças entre a fala e a canção e que questionam a origem da música e as formas como ela se relaciona com a linguagem. 0 primeiro texto da seção foi extraído do Essay on the origin of languages de Jean-Jacques Rousseau, onde encontramos sua teoria a respeito de uma origem comum para a fala e a música. Segundo o autor, música e fala teriam emergido juntas no nascimento da sociedade e, somente algum tempo depois, teriam se separado em modos verbais e musicais de comunicação. Jaques Derrida se contrapõe ao ponto de vista 
de Rousseau, defendendo que a fala e o canto nunca estiveram realmente juntos, mas sim, em constante processo de diferenciação desde o início da humanidade. 0 texto seguinte, de Charles Myers, também discute a origem da música e sua raiz comum à fala dentro da evolução humana. Geoge List, através do uso de um espectrógrafo, buscou categorizar a grande diversidade de formas vocais encontradas ao redor do mundo; o fragmento extraído do trabalho de Richard Wagner aborda paradoxos nas relações entre a poesia e a música; e o artigo de David Hughes apresenta o uso de sistemas de sílabas para transmitir intervalos melódicos no processo de ensino da flauta noh japonesa. Finalmente, o trabaIho de George Herzog discute o uso de tambores como imitação da fala em uma tribo africana.

Na segunda parte, Song, text and voice, encontramos sete trabalhos que consideram as relações de complementaridade entre texto e voz na canção e entre o significado das palavras e os outros aspectos do canto. 0 texto de Simon Frith aborda as várias vozes que se encontram na canção e as relações de identidade entre o próprio e o outro daí decorrentes. Steven Feld e seus colaboradores discutem o jogo entre o sentido do texto e os recursos vocais utilizados por um cantor norte-americano de música country. Roland Barthes apresenta a música como uma forma de linguagem e discute a musicalidade de textos transformados em canção. Tim Riley analisa a canção Hey Jude, dos Beatles, seu processo de composição e os significados de sua parte final, desprovida de palavras. Virginia Danielson analisa as relações entre texto e qualidade vocal em uma performance do Alcorão islâmico. Sheila Dhar e Peter Manuel analisam a voz dentro da canção indiana Thumri, destacando aspectos de sua relação com o erótico e com o desejo.

A terceira parte, Song performance and society, apresenta seis escritos que consideram o canto enquanto performance e dentro de seu contexto social. Viktor Zuckerkandl discute o significado do lugar social da canção, onde a voz do indivíduo passa a representar a voz de um grupo e a funcionar como um importante fator de identidade. 0 trabalho de Hiromi Sakata aborda aspectos do público e do privado e suas relações com questões sobre o gênero, dentro da performance do lullaby no Afeganistão. Susan McClary aborda questões sobre raça, classe social e gênero em seu estudo de caso sobre a ópera Carmen, de Georges Bizet. Richard Middleton discute o blues como forma de expressão não somente dos africanos-americanos, mas também dos brancos norte-americanos. Christopher Waterman descreve a juju music da Nigéria e as funções sociais de sua execução ao vivo. Robert Walser discute o papel das palavras e dos aspectos musicais na transmissão das mensagens políticas do grupo rap Public Enemy. Finalmente, Jan Bolwell analisa a interação entre gestos e linguagem na transmissão da mensagem das canções interpretadas por Keri Kaa.
A quarta parte, Song and ritual, reúne sete trabalhos que focam na canção em contextos de performances rituais sagradas ou profanas e na adaptação ou representação encenada de rituais em performances musicais. 0 artigo de Palmer e Patten descreve e situa canções do gênero Wassails, utilizadas no contexto de remanescentes rituais de inverno no distrito de Somerset, Inglaterra. 0 fragmento do trabalho de Frank Howes aborda o gênero de canção Carols cujos textos parecem sofrer marcada influência da música gospel. Robert Hayburn discute a relação entre letra e música ao abordar o uso de textos sagrados na forma vernácula na música religiosa católica do século quatorze. Marina Roseman discute o papel curativo das canções em rituais do povo Temiar da Malásia. Naquele contexto, as canções atuam como pontes de ligação entre doentes e seus guias espirituais em direção à cura. Elizabeth Tolbert descreve o lamento, ao mesmo tempo espontâneo e estilizado, dos refugiados soviéticos da região de Karelia, no sudeste da Finlândia. Os artigos de Richard Taruskin e de Pieter van der Toorn analisam um tradicional ritual russo de casamento e seu uso por Stravinsky na preparação de sua peça de balé Les Noces. A discussão sobre a música em contextos rituais ganha nova dimensão ao analisar-se sua apropriação em uma performance encenada.

A quinta e última parte, Words music and narrative, reúne oito trabalhos que consideram as relações entre palavras e música na construção de narrativas. 0 texto gerado a partir de uma entrevista realizada com Mauro Geraci descreve a arte dos "cantadores" de histórias (storytellers) sicilianos que usam canções e palavras para contar histórias com temas antigos e contemporâneos. Nesse tipo de arte, a música presente no acompanhamento da guitarra apresenta-se como suporte para o desenvolvimento da história contada. Edward Cone desvenda as várias vozes, literais e metafóricas, presentes na ópera ocidental, partindo dos cantores, englobando as linhas instrumentais e chegando até a voz do compositor. Carolyn Abbate analisa as narrativas musicais do século dezenove com foco no papel da voz na ária Bell Song da ópera Lakmé, de Léo Delibes. Gordon Williams apresenta os processos de trabalho na criação de uma cantata, descrevendo as relações de parceria entre 0 compositor e o libretista e discute a pertinência de se analisar os textos de tais obras fora de seu contexto musical. A entrevista realizada com o compositor de canções para a Broadway, Stephen Sondheim, apresenta aspectos de sua técnica composicional e de sua visão sobre as diferenças entre a ópera e o teatro musical. 0 letrista de canções para musicais da década de 1940 na Broadway, Oscar Hammerstein, discute sua prática na criação de letras, com enfoque para aspectos como rima, ritmo e fonética. Os excertos da novela autobiográfica de Amit Chaudhuri traz um pouco de sua experiência adquirida em sessões de música na Índia e de sua relação com a voz dentro de canções indianas. Encerra a seção e o volume, um extrato do livro No Caminho de Swann, onde Marcel Proust descreve a experiência de seu protagonista ao ouvir uma sonata composta pelo compositor fictício Vinteuil. 
A antologia reúne desde trabalhos escritos no século dezoito até textos inéditos, elaborados especialmente para o livro. Por se tratar de uma coleção de textos utilizados para um seminário de pós-graduação, alguns trabalhos são apresentados no volume em excertos bastante reduzidos, o que pode dificultar a compreensão mais ampla do pensamento dos autores. Um exemplo disso é o fragmento do texto Working-class 'country', assinado por Steven Feld e colaboradores. Nesse caso especifico, o texto merece ser lido na íntegra, ou melhor, talvez apenas com 0 livro Real Country de Aaron Fox, o leitor poderá contextu- alizar adequadamente as proposições geradas pelo trabaIho desenvolvido. Nesse sentido, a intervenção presencial do professor parece ser fundamental para suprir lacunas deixadas pela forçosa redução de alguns textos. Ainda assim, a significativa diversidade dos trabalhos, aliada ao abrangente período temporal em que foram escritos, nos oferece uma interessante visão do pensamento existente sobre o tema e faz da coletânea um rico material para o aprofundamento da discussão sobre as interações entre as palavras, a voz e a música.

Maurilio Andrade Rocha é Professor da Escola de Belas Artes da UFMG onde ministra disciplinas relacionadas à música e à voz no teatro. Integra o grupo de pesquisa NACE (Núcleo de Pesquisa Transdisciplinar em Artes Cênicas) e é Doutor Colaborador do INET-MD (Instituto de Etnomusicologia - Música e Dança) da Universidade Nova de Lisboa. Suas investigações e publicações têm se concentrado nas ligações entre a música popular, o teatro e a sociedade. 